\title{
The Reliability and Validity of the Mini-Mental State Examination in the Elderly Croatian Population
}

\author{
Marina Boban ${ }^{a, b}$ Branko Malojčića ${ }^{a, b} \quad$ Ninoslav Mimica ${ }^{b, c}$ \\ Sunčica Vukovićb Ivan Zrilićb Patrick R. Hofe Goran Šimićb,d \\ aDepartment of Cognitive Neurology, University Hospital Centre, ${ }^{\text {bS }}$ chool of Medicine, University of Zagreb, \\ 'University Psychiatric Hospital Vrapče, and dCroatian Institute for Brain Research, Zagreb, Croatia; ${ }^{\mathrm{e} M o u n t}$ Sinai \\ School of Medicine, New York, N.Y., USA
}

\section{Key Words}

Mini-Mental State Examination - Elderly population • Alzheimer's disease $\cdot$ Epidemiology $\cdot$ Screening $\cdot$ Cutoff point $\cdot$ Croatia

\begin{abstract}
Aim: The aim of this study was standardization and validation of the Mini-Mental State Examination (MMSE) in the general Croatian aging population. Methods: Three-hundred and forty-four participants underwent the MMSE test, 217 cognitively healthy subjects without neurological and psychiatric disorders and 127 patients with mild cognitive impairment $(\mathrm{MCl})$ or dementia. Results: The optimal cutoff point for screening of the general Croatian population (cognitively healthy vs. $\mathrm{MCl}$ and dementia) is $26 / 27$; in the Croatian population aged $\geq 65$ years, the cutoff point is $24 / 25$, whereas for screening of highly educated persons ( $\geq 14$ years of education) aged $\geq 65$ years a higher cutoff point should be used (26/27). Conclusions: MMSE results when standardized and validated in a certain population might better contribute to recognition of the individuals at risk that should be directed to dementia outpatient clinics.
\end{abstract}

\section{KARGER}

Fax +41613061234

E-Mail karger@karger.ch

www.karger.com
(C) 2012 S. Karger AG, Basel

$1420-8008 / 12 / 0336-0385 \$ 38.00 / 0$

Accessible online at: www.karger.com/dem

\section{Introduction}

The Mini-Mental State Examination (MMSE) is the most commonly used screening test for the assessment of cognitive functioning [1]. Apart from bedside quantification of cognitive impairment, it is of great help in estimating the patients' cognitive change over time and also in monitoring therapeutic response in clinical trials [2]. During the years, the test was found to be relatively sensitive in diagnosing cases of overt dementia; however, its specificity decreases significantly when cognitively healthy individuals and patients with mild cognitive impairment (MCI) should be discriminated. Apart from evident advantages of the MMSE test (e.g. short training required, quick and easy administration, good accessibility), there are also some disadvantages: (1) dependence on demographic variables such as age $[3,4]$ and education [4-6] where younger and highly educated persons score more, therefore, necessitating adjustment of the scores to these variables $[7,8]$; (2) the effect of cultural differences, lifestyle, head trauma, and concomitant depression on total scores [9]; (3) neglecting important domains of cognitive functioning (e.g. executive function) 
that may be impaired early in dementia types other than Alzheimer's disease (AD).

The MMSE was introduced in Croatia as a screening protocol for dementia shortly after its publication in 1975 [1]. Despite its widespread use in screening for cognitive impairment, there was no study so far with the aim of standardization and validation of MMSE in Croatian population; therefore, detailed guidelines for administration and interpretation of the test are missing. The aim of this study was to obtain standardization of the MMSE in an ageing Croatian population with the emphasis on the effect of age, gender, and education on MMSE score and cutoff points as well as in different clinical settings (cognitively healthy individuals $\geq 45$ years vs. MCI and demented patients $\geq 45$ years, cognitively healthy individuals $\geq 45$ years vs. demented patients $\geq 45$ years, cognitively healthy individuals $\geq 65$ years vs. demented patients $\geq 65$ years, cognitively healthy individuals $\geq 65$ years vs. AD patients $\geq 65$ years). Finally, we interpreted our results in the context of previously published studies.

\section{Subjects and Methods}

\section{Subjects}

Subjects were recruited from general practitioners' offices as well as Dementia Outpatient Clinic, Department of Cognitive Neurology, University Hospital Centre Zagreb from April 2009 to December 2011. Native Croatian speakers of 45 years of age or more were included in the study. Exclusion criteria were history of psychiatric illness (e.g. delirium, depression, and psychosis), history of head trauma, chronic alcohol intake, neurological illnesses with possible cognitive deficits (e.g. tumors and infections of the central nervous system), physical disorder or general medical condition affecting the CNS (e.g. hypothyroidism, multisystemic diseases).

\section{Methods}

All eligible individuals underwent the MMSE test. The original English version of the MMSE test from 1975 [1] was translated into Croatian by two authors (M.B. and B.M.) with minor changes made based on different translations of verbal instructions. The original style of the MMSE was closely followed with 11 questions and a maximum total score of 30 . We used the word TORBA ('bag') for the backwards spelling in the question that estimates attention. Informed consent was obtained before administration of the tests from all subjects participating in the study or their legally assigned caregivers.

All subjects suspected of having cognitive impairment were referred to the Dementia Outpatient Clinic for additional routine evaluation: neurological examination, detailed neurocognitive and neuropsychological evaluation, blood test analysis including complete blood count, electrolytes, thyroid function tests, vitamin $\mathrm{B}_{12}$ and folic acid levels, ECG and neuroimaging (brain MRI). The imaging studies were carried out on a 1.5- or 3-tesla scanner.

Subjects included in the study were finally divided into two groups: (1) cognitively healthy individuals (without subjective and objective cognitive deficits; recruited from general practitioners' offices, or family members and caregivers of patients), and (2) patients with cognitive impairment (MCI or overt dementia). The diagnoses were established by a team of experienced neurologists and psychiatrists according to the currently recognized clinical criteria for different types of dementia. The diagnosis of 'probable' AD was made according to the criteria of the National Institute of Neurological and Communicative Diseases and Stroke/Alzheimer's Disease and Related Disorder Association (NINCDS-ADRDA) [10]. Among patients who fulfilled the criteria by Román et al. [11] for vascular dementia, we included only those with subcortical vascular dementia with specific $\mathrm{MRI}$ changes $\left(\mathrm{T}_{2}\right.$-weighted subcortical vascular changes without finding of cortical lesions). These patients were included in the group of subcortical vascular cognitive impairment (VCI). The diagnosis of frontotemporal lobar degeneration (FTLD) was made according to the criteria by Neary et al. [12]. The diagnosis of diffuse Lewy body disease (DLBD) was made according to the clinical criteria of the consortium on DLBD [13]. The diagnosis of Parkinson's disease dementia (PDD) was made according to the clinical diagnostic criteria for PDD [14]. The diagnosis of MCI was made according to Petersen's criteria and the criteria of the International Working Group on Mild Cognitive Impairment $[15,16]$. Final diagnoses were based on additional results of diagnostic workup and a prolonged follow-up period of up to 12 months. The study was approved by the ethics committee of the University Hospital Center Zagreb. All patients were naive to specific therapy for dementia (e.g. acetylcholinesterase inhibitors and memantine) at the time of inclusion to the study. To quantify severity of dementia, we used the clinical dementia rating scale classifying patients into very mild (MCI), mild, moderate, or severe stages of dementia [17].

\section{Statistical Analysis}

Subjects were divided according to the cognitive status (with or without cognitive impairment or dementia), type and severity of dementia as well as age, gender and education. Subjects with MCI were divided according to the primary cognitive deficit: memory (amnestic type of MCI) or other (nonamnestic type of MCI). Data are presented as mean \pm standard deviation and median with range. Sensitivities, specificities, positive predictive values (PPVs), and negative predictive values (NPVs) were calculated at different cutoff points $(23 / 24$, $24 / 25,25 / 26,26 / 27)$ between subjects without cognitive impairment and different subsets of cognitively impaired patients (e.g. MCI plus demented patients $\geq 45$ years, demented patients $\geq 45$ years, demented patients $\geq 65$ years, AD patients $\geq 65$ years). The final cutoff points on the MMSE were derived from the receiver operating characteristic curve analysis when the sum of sensitivity and specificity was maximized for each subset of patients. Correlations between MMSE scores and severity of dementia as well as other demographic data were assessed by calculating Spearman's rank correlation coefficients 
Fig. 1. MMSE scores in cognitively healthy individuals, subjects with MCI and subjects with mild, moderate, and severe dementia aged $\geq 45$ years. Data are presented as box plots. Boxes represent the 25th, 50th (median), and 75th percentiles. Circles represent mild outliers.

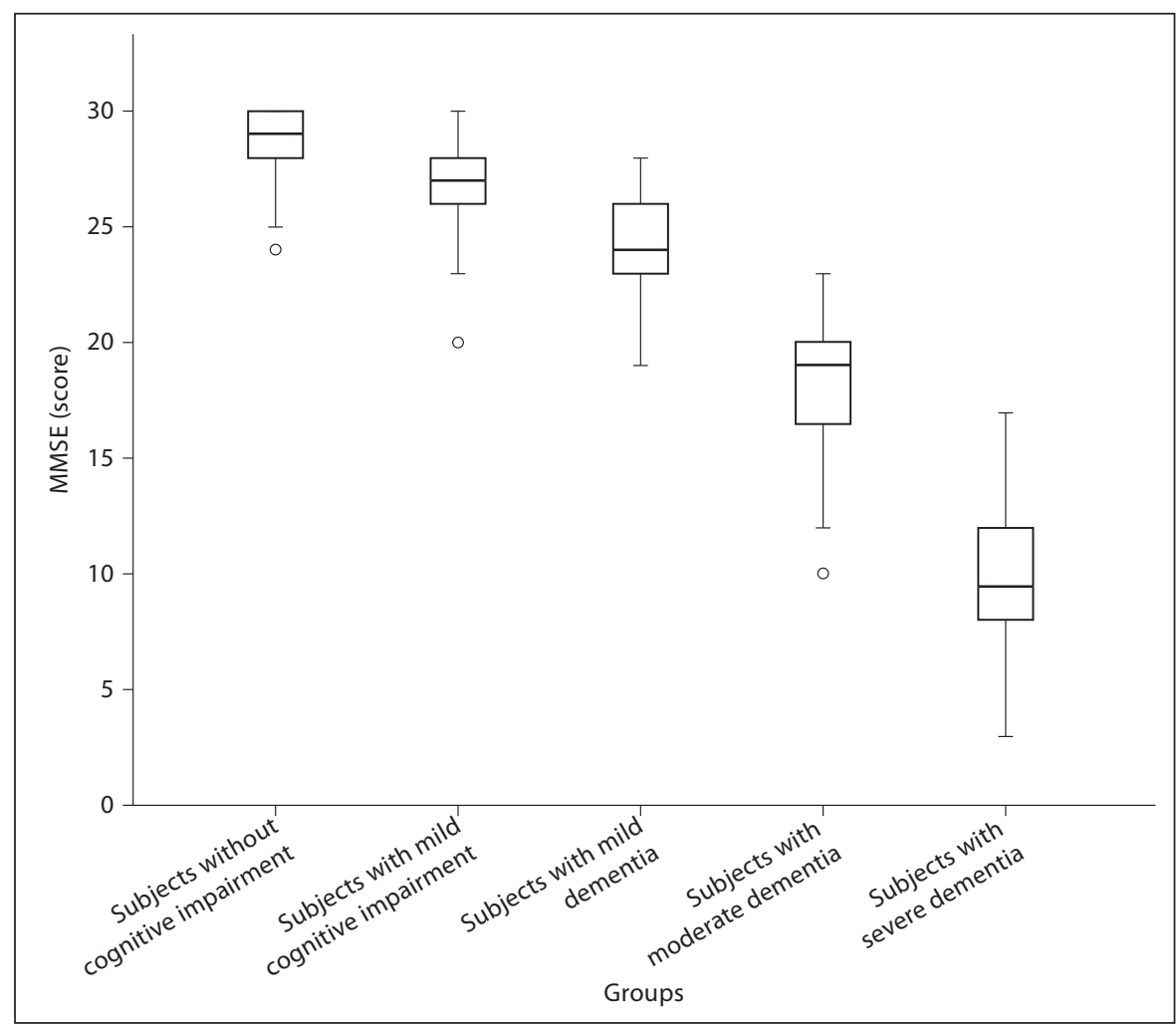

(r). Statistical analysis was performed using SPSS v.11.0.1; p values lower than 0.05 were considered statistically significant.

\section{Results}

Of the 344 participants recruited in the study, 217 subjects had no cognitive impairment and 127 patients had MCI or dementia. In the dementia group, there were 53 patients with AD, 41 with VCI, 14 with FTLD, 7 with DLBD, 5 with PDD, 29 with amnestic type of MCI, 16 with nonamnestic type of MCI, and 7 patients with other types of dementia ( 3 with posterior cortical atrophy, 2 with corticobasal degeneration, and 2 with normal pressure hydrocephalus). Except for significantly younger ages of subjects without cognitive impairment as well as of patients with FTLD or MCI, there were no other statistically significant differences in age, education and gender among groups. Stratification and demographic data of participants are shown in table 1. The mean MMSE score of subjects without cognitive impairment was 27.9 \pm 2.1 points (median 28.0, with a range of 6.0 ), whereas MMSE scores of MCI, mild, moderate and severe dementia patients were $26.9 \pm 2.3,23.9 \pm 2.5,18.3 \pm 2.7$, and
$10.0 \pm 3.2$ points, respectively. Medians with interquartile ranges (25th-75th percentile) of MMSE scores are graphically presented in figure 1. Additionally, mean values and $\mathrm{SD}$ as well as medians with ranges of MMSE scores are presented in table 1. Mean MMSE scores for subjects $\geq 65$ years old were as follows: $27.1 \pm 2.7$ in subjects without cognitive impairment, $24.0 \pm 2.5$ in a group of mildly demented patients, $17.6 \pm 2.9$ in a group of moderately demented patients, and $9.7 \pm 2.8$ in a group of severely demented patients. There was no statistically significant difference in education, gender, or age among groups. Additionally, no statistical difference was found in MMSE scores between female and male subjects without cognitive impairment $(28.03 \pm 2.3$ for women, $27.8 \pm 1.7$ for men). Distribution of MMSE scores in subjects aged $\geq 65$ years stratified by the presence of cognitive impairment/ dementia and severity of dementia (mild, moderate, severe) is shown as medians and interquartile ranges (25th75 th percentile) in figure 2. Medians with interquartile ranges of MMSE scores of cognitively healthy individuals and AD patients (stratified by severity of dementia) $\geq 65$ years of age are graphically presented in figure 3 .

Table 2 presents sensitivities, specificities, PPVs, and NPVs for 4 different settings (cognitively healthy indi- 
Table 1. Demographic data of participants



Data are presented as mean \pm SD and median (range). aMCI = Amnestic mild cognitive impairment; naMCI = nonamnestic mild cognitive impairment.

viduals $\geq 45$ years vs. MCI plus demented patients $\geq 45$ years, cognitively healthy individuals $\geq 45$ years vs. demented patients $\geq 45$ years, cognitively healthy individuals $\geq 65$ years vs. demented patients $\geq 65$ years, cognitively healthy individuals $\geq 65$ years vs. AD patients $\geq 65$ years) with marked values of sensitivities, specificities, PPVs and NPVs for specific ('ideal') cutoff points. The cutoff point was 26/27 when comparing cognitively healthy individuals $\geq 45$ years of age to the group of demented patients alone or together with MCI patients of the same age group. When comparing cognitively healthy individuals aged $\geq 65$ years to demented patients aged $\geq 65$ years, the cutoff point was $24 / 25$, while when comparing cognitively healthy individuals aged $\geq 65$ years to strictly AD patients aged $\geq 65$ years, the cutoff point was $23 / 24$. PPVs were extremely high in all above-mentioned clinical settings at cutoff points; however, NPVs were not satisfactory in two situations: when comparing cognitively healthy individuals $\geq 45$ years of age to the joint group of $\mathrm{MCI}$ and demented patients aged $\geq 45$ years (NPV = $71.32 \%$ ), and when comparing cognitively healthy individuals aged $\geq 65$ years to demented patients aged $\geq 65$ years $(\mathrm{NPV}=60.71 \%)$. The results are presented in table 2. When comparing the cognitively healthy and $\mathrm{AD}$ groups aged $\geq 65$ years, there was a gender difference in cutoff points (23/24 for men, 24/25 for women). In a cohort of highly educated patients ( $\geq 14$ years of education), the cutoff point was $26 / 27$ with sensitivity of $72.73 \%$, specificity of $96.67 \%$, PPV of $96 \%$ and NPV of $76.32 \%$ when comparing cognitively healthy individuals to MCI and demented patients aged $\geq 65$ years. At the cutoff point of $23 / 24$, the sensitivity and specificity were 45.45 and $100 \%$, respectively, with a PPV of 100 and an NPV of $62.5 \%$ for the same clinical setting. The cutoff point was the same (26/27) when comparing solely highly educated AD patients to cognitively healthy individuals with very high sensitivity, specificity, PPV and NPV (95.45, $96.67,95.45$ and $96.67 \%)$. At the cutoff point of $23 / 24$, the sensitivity and specificity were $68.18 \%$ and $100 \%$, respectively, with PPV of $100 \%$ and NPV of $81.08 \%$ (data not shown).

Correlations between MMSE scores, age, education, and disease stage in select groups of patients or cognitively healthy individuals are presented in table 3. 
Fig. 2. MMSE scores in cognitively healthy individuals and subjects with mild, moderate and severe dementia aged $\geq 65$ years. Data are presented as box plots. Boxes represent the 25th, 50th (median), and 75 th percentiles.

Fig. 3. MMSE scores in cognitively healthy individuals and subjects with mild, moderate, and severe $\mathrm{AD}$ aged $\geq 65$ years. Data are presented as box plots. Boxes represent the 25th, 50th (median), and 75th percentiles. The circle represents a mild outlier.
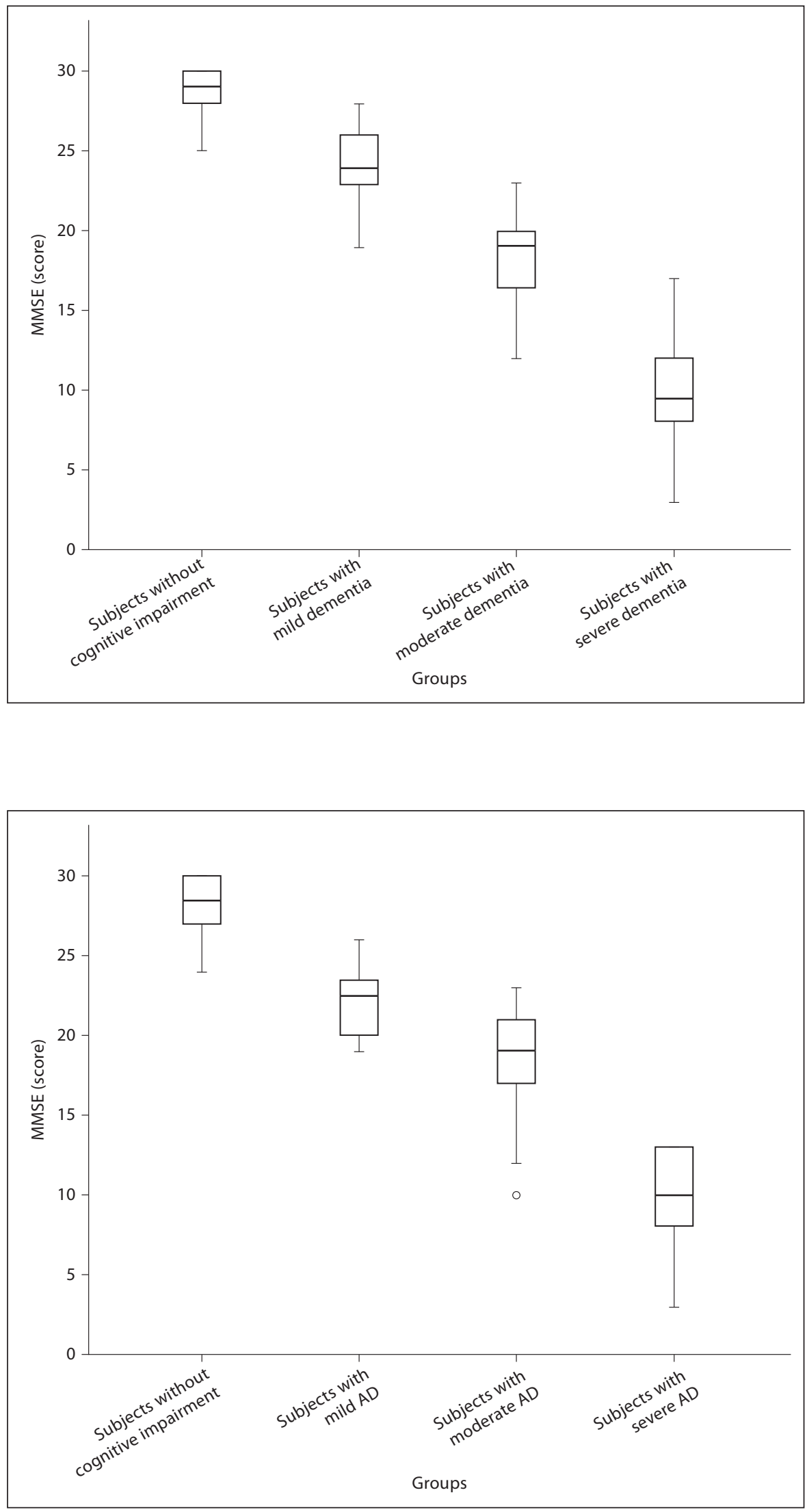
Table 2. Sensitivities, specificities, PPV and NPV in different settings of cutoff values

\begin{tabular}{|c|c|c|c|c|c|c|c|c|c|c|c|c|c|c|c|c|}
\hline $\begin{array}{l}\text { MMSE } \\
\text { cutoff }\end{array}$ & \multicolumn{4}{|l|}{ Sensitivity } & \multicolumn{4}{|l|}{ Specificity } & \multicolumn{4}{|l|}{ PPV } & \multicolumn{4}{|l|}{ NPV } \\
\hline $3 / 24$ & 53.74 & 75.51 & 77.65 & 92.50 & 100 & 100 & 100 & 100 & 100 & 100 & 100 & 100 & 60.00 & 80.95 & 48.65 & 85.71 \\
\hline $24 / 25$ & 60.64 & 84.69 & 87.06 & 95.00 & 99.02 & 99.02 & 94.44 & 94.44 & 98.89 & 98.81 & 98.67 & 97.44 & 63.52 & 87.07 & 60.71 & 89.47 \\
\hline
\end{tabular}

Data are presented in percentages. $\mathrm{D}=$ Demented.

Table 3. Correlations between MMSE scores, age, education and stage of the disease in selected groups of patients/cognitively healthy individuals

\begin{tabular}{llc}
\hline & MMSE & \\
\hline Subjects without & age & -0.072 \\
cognitive impairment & education & 0.079 \\
\hline MCI + demented patients & age & $-0.272^{* *}$ \\
& education & $0.208^{*}$ \\
& disease stage & $-0.871^{*}$ \\
\hline Only demented patients & age & $-0.210^{*}$ \\
& education & 0.246 \\
& disease stage & $-0.838^{* *}$ \\
\hline Only AD patients & age & -0.229 \\
& education & 0.128 \\
& disease stage & $-0.710^{* *}$ \\
\hline
\end{tabular}

$* \mathrm{p}=0.05$; correlation is significant (2-tailed).

$* * \mathrm{p}=0.01$; correlation is significant (2-tailed).

There was no statistically significant correlation between MMSE score and age or level of education in a cognitively healthy group of subjects. A significantly negative correlation between MMSE score and age and MMSE score and disease stage was found in a joint group of cognitively impaired patients (MCI patients and patients with overt dementia). In two other groups (patients with overt dementia and $\mathrm{AD}$ patients), as expected there was a significantly negative correlation between MMSE score and stage of the disease. A positive correlation between MMSE score and level of education was found only in a group of patients with overt dementia.

\section{Discussion}

The aim of this study was to standardize the MMSE test for the elderly Croatian population with the main focus on finding cutoff points for different clinical settings. According to the first study by Folstein et al. [1] in 1975, the cutoff point for differentiation between demented patients and nondemented individuals was 23/24; however, this result was obviously biased toward the lower MMSE score due to inclusion of solely demented psychiatric in-patients (patients in severe stages of the disease). Later results had shown that the MMSE was less accurate in distinguishing cognitively healthy individuals and patients with dementia in the community populations, especially if MCI patients were included. In our study, at the cutoff point of 23/24 (proposed by Folstein) the sensitivity was $75.51 \%$ and specificity was $100 \%$ with a PPV of $100 \%$ for differentiation of cognitively healthy individuals and patients with overt dementia. These results are in concordance with the previously published articles with sensitivity ranging mostly between 76 and $87 \%$ and specificities around $90-95 \%$ [18-22]; however, lower sensitivities were also reported (around 50-65\%) $[23,24]$.

By extending the group of overt dementia patients with MCI patients, the optimal cutoff point in our study raised to $26 / 27$ with a sensitivity of $73.47 \%$ and a specificity of $95.10 \%$. The same cutoff point was suggested in the study published by O'Bryant et al. [25] with roughly similar sensitivity and specificity (69 and 91\%, respectively) and some other publications (the latest MMSE guidelines reported a sensitivity of $83 \%$ and specificity of $66 \%)$ [22, 26, 27]. Additionally, in our study the optimal cutoff point for discrimination between cognitively healthy individuals and patients with overt dementia 
was $26 / 27$ with sensitivity of $93.88 \%$ and specificity of $95.10 \%$. The high cutoff points found in our study might be explained by more frequent recruitment of patients in the initial stages of dementia as well as higher percentage of highly educated persons than in the general population. However, the cutoff point significantly decreased to $24 / 25$ with inclusion of patients/cognitively healthy individuals aged $\geq 65$ years old with a sensitivity of $87.06 \%$ and specificity of $94.44 \%$. The limitation of the MMSE test is that it neglects certain domains of cognitive functioning (e.g. executive function) that are damaged in early stages of dementia types other than $\mathrm{AD}$ meaning that some patients may achieve a very high MMSE score despite significant cognitive impairment. Therefore, we evaluated only patients with $\mathrm{AD}$ to determine the accuracy of the MMSE in distinguishing $\mathrm{AD}$ and cognitively healthy patients aged $\geq 65$ years. The cutoff point was $23 / 24$ as Folstein proposed in 1975 with a sensitivity of $92.50 \%$ and specificity of $100 \%$ [1]. The cutoff point of $24 / 25$ was proposed by Morales et al. [28] with a sensitivity of $85 \%$ and specificity of $90 \%$ for distinguishing the same cohort. This cutoff point reached high sensitivity (95\%) and specificity (94.44\%) in our study as well. Additionally, higher cutoff points were proposed for screening of highly educated individuals. O'Bryant et al. [25] suggested a cutoff point of $26 / 27$ with an optimal ratio of sensitivity (89\%) and specificity (91\%) and an overall correct classification rate of $90 \%$. The same cutoff point for screening highly educated individuals of $\geq 65$ years was optimal in our study with sensitivity of $72.73 \%$, specificity of $96.67 \%$, PPV of $96 \%$, and NPV of $76.32 \%$.

The latest MMSE guidelines proposed a cutoff point of $26 / 27$ for screening the general population [26]. In our study, the cutoff level was the same for screening the general population irrespective of inclusion of MCI patients; however, as expected sensitivity and specificity were significantly lower when MCI cases were included. Additionally, the same cutoff point was found for screening of highly educated individuals.
To the best of our knowledge, except for a Slovenian study [24], there are no similar studies in Croatia and surrounding Southeast European countries that share comparable cultural, educational and historic backgrounds. Our results were very similar to those of the Slovenian group [24]. Additionally, the education level of the cognitively healthy population in our study was comparable to the last population registration in Croatia (52.9\% individuals who finished secondary school in our cohort compared to $47 \%$ in the Croatian population). The higher percentage of highly educated individuals in our cohort was probably due in part to the criterion of inclusion of only patients who are $\geq 45$ years of age, and not all age groups.

In conclusion, the result of our study shows that the optimal cutoff point for screening the Croatian population overall is $26 / 27$. For screening of a population of $\geq 65$ years, the cutoff level is $24 / 25$, whereas for screening of highly educated persons ( $\geq 14$ years of education) aged $\geq 65$ years, a higher cutoff point should be used (26/27). The aim of this study is not to encourage the diagnosis of cognitive impairment based solely on the MMSE score, but rather to direct individuals at risk with a subjective or objective cognitive complaint to the dementia outpatient clinic for an additional neurocognitive and neuropsychological evaluation.

\section{Acknowledgements}

This work was supported by the Croatian Science Foundation grant No. 09/16 ('Detection and tracking of biological markers for early therapeutic intervention in sporadic Alzheimer's disease').

\section{Disclosure Statement}

There is no conflict of interest.

\section{References}

1 Folstein MF, Folstein SE, McHugh PR: Minimental state. A practical method for grading the cognitive state of patients for the clinician. J Psychiatr Res 1975;12:189-198.

2 Strauss E, Sherman EMS, Spreen O: A Compendium of Neuropsychological Tests: Administration, Norms, and Commentary, ed 3 . Oxford, Oxford University Press, 2006.

Mini-Mental State Examination in Elderly Croatian Population
3 Bleecker ML, Bolla-Wilson K, Kawas C, Agnew J: Age-specific norms for the MiniMental State Exam. Neurology 1988;38: 1565-1568.

-4 Aevarsson O, Skoog I: A longitudinal population study of the mini-mental state examination in the very old: relation to dementia and education. Dement Geriatr Cogn Disord 2000;11:166-175.
5 O'Connor DW, Pollitt PA, Treasure FP, Brook $\mathrm{CPB}$, Reiss BB: The influence of education, social class, and sex on Mini-Mental State scores. Psychol Med 1989;19:771-776.

-6 Brayne C, Calloway P: The Association of Education and socioeconomic status with the Mini-Mental State Examination and the clinical diagnosis of dementia in elderly people. Age Ageing 1990;19:91-96. 
$>7$ Ylikosky R, Erkinjuntti T, Sulkava R, Jura $\mathrm{K}$, Tilvis R, Valvanne J: Correction for age, education and other demographic variables in the use of Mini-Mental State Examination in Finland. Acta Neurol Scand 1991;85: 391-396.

8 Katzman R: Education and the prevalence of dementiaand Alzheimer's disease. Neurology 1993;43:13-20.

$\checkmark 9$ Tombaugh TN, McIntyre NJ: The MiniMental State Examination: a comprehensive review. J Am Geriatr Soc 1992;40:922-935.

- 10 McKhann G, Drachman D, Folstein M, Katzman R, Price D, Stadlan EM: Clinical diagnosis of Alzheimer's disease: report of the NINCDS-ADRDA Work Group under the auspices of Department of Health and Human Services Task Force on Alzheimer's Disease. Neurology 1984;34:939-944.

$\checkmark 11$ Román GC, Tatemichi TK, Erkinjuntti T, Cummings JL, Masdeu JC, Garcia JH, Amaducci L, Orgogozo JM, Brun A, Hofman A, et al: Vascular dementia: diagnostic criteria for research studies. Report of the NINDSAIREN International Workshop. Neurology 1993;43:250-260.

-12 Neary D, Snowden JS, Gustafson L, Passant U, Stuss D, Black S, Freedman M, Kertesz A, Robert PH, Albert M, Boone K, Miller BL, Cummings J, Benson DF: Frontotemporal lobar degeneration: a consensus on clinical diagnostic criteria. Neurology 1998;51: 1546-1554.

13 McKeith IG, Dickson DW, Lowe J, Emre M, O’Brien JT, Feldman H, Cummings J, Duda JE, Lippa C, Perry EK, et al: Diagnosis and management of dementia with Lewy bodies: third report of the DLB Consortium. Neurology 2005;65:1863-1872.
14 Emre M, Aarsland D, Brown R, Burn DJ, Duyckaerts C, Mizuno Y, Broe GA, Cummings J, Dickson DW, Gauthier S, et al: Clinical diagnostic criteria for dementia associated with Parkinson's disease. Mov Disord 2007;22:1689-1707.

15 Petersen RC: Mild cognitive impairment as a diagnostic entity. J Intern Med 2004;256: 183-194.

16 Winblad B, Palmer K, Kivipelto M, Jelic V, Fratiglioni L, Wahlund LO, Nordberg A, Bäckman L, Albert M, Almkvist O, et al: Mild cognitive impairment - Beyond controversies, towards a consensus: report of the International Working Group on Mild Cognitive Impairment. J Intern Med 2004;256: 240-246.

17 Morris JC: The Clinical Dementia Rating (CDR): current version and scoring rules. Neurology 1993;43:2412-2414.

18 O'Connor DW, Pollitt PA, Hyde JB, Fellows JL, Miller ND, Brook CP, Reiss BB: The reliability and validity of the Mini-Mental State in a British community survey. J Psychiatr Res 1989;23:87-96.

19 Small BJ, Herlitz A, Fratiglioni L, Almkvist O, Backman L: Cognitive predictors of incident Alzheimer's disease: a prospective longitudinal study. Neuropsychology 1997;11: 413-420.

20 Cossa FM, Della Sala S, Musicco M, Spinnler H, Ubezio MC: Comparison of two scoring systems of the Mini-Mental State Examination as a screening test for dementia. J Clin Epidemiol 1997;50:961-965.

21 Gagnon M, Letenneur L, Dartigues JF, Commenges D, Orgogozo JM, Barberger-Gateau $\mathrm{P}$, Alpérovitch A, Décamps A, Salamon R: Validity of the Mini-Mental State examination as a screening instrument for cognitive impairment and dementia in French elderly community residents. Neuroepidemiology 1990;9:143-150.
22 Mulligan R, Mackinnon A, Jorm AF, Giannakopoulos P, Michel JP: A comparison of alternative methods of screening for dementia in clinical settings. Arch Neurol 1996;53: 532-536.

23 Kukull WA, Larson EB, Teri L, Bowen J, McCormick W, Pfanschmidt ML: The MiniMental State Examination score and the clinical diagnosis of dementia. J Clin Epidemiol 1994;47:1061-1067.

24 Rakusa M, Granda G, Kogoj A, Mlakar J, Vodusek DB: Mini-Mental State Examination: standardization and validation for the elderly Slovenian population. Eur J Neurol 2006; 13:141-145.

-25 O'Bryant SE, Humphreys JD, Smith GE, Ivnik RJ, Graff-Radford NR, Petersen RC, Lucas JA: Detecting dementia with the minimental state examination in highly educated individuals. Arch Neurol 2008;65:963-967.

26 De Marchis GM, Foderaro G, Jemora J, Zanchi F, Altobianchi A, Biglia E, Conti FM, Monotti R, Mombelli G: Mild cognitive impairment in medical inpatients: the MiniMental State Examination is a promising screening tool. Dement Geriatr Cogn Disord 2010;29:259-264.

27 Folstein MF, Folstein SE, Fanjiang G: MiniMental State Examination Clinical Guide. Lutz, Psychological Assessment Resources, Inc, 2001.

28 Morales JM, Gonzalez-Montalvo JI, Bermejo F, Del-Ser T: The screening of mild dementia with a shortened Spanish version of the Informant Questionnaire on Cognitive Decline in the Elderly. Alzheimer Dis Assoc Disord 1995;9:105-111. 